\title{
ARTISTIC FORMS AND ETHNIC IDENTITY IN NIGERIAN PAINTING
}

\author{
Johnson Adelani Abodunrin $\mathbb{0}^{凶}$ \\ PhD, Department of Fine and Applied Arts, Ladoke Akintola University of Technology, Oyo State, Nigeria
}

\author{
Research Article \\ PII: S238315532100001-10 \\ Received: 29 March 2021 \\ Revised: 25 May 2021 \\ Published: 15 June. 2021
}

Corresponding author:

E-mail: jaabodunrin@lautech.edu.ng

\begin{abstract}
This paper discusses the artistic forms and ethnic identity of paintings in Nigerian art schools. Artists in Nigeria used diverse forms to represents images that are peculiar to their ethnic groups to achieve a distinctive identity. Data for the study were obtained from paintings of different ethnic groups found in the various regions of the Art schools in Nigeria. The art schools have been the centre for manifestation of indigenous forms in Nigeria. The Schools has been noted with individualism in form depiction that is characterized by elongation of forms, abstraction, semi-realistic with northern architecture. In the South and Eastern part of the country their paintings depict day to day activities using naturalism and symbolic representation of forms. Each region uses indigenous forms to portray ethnic identity and this invariably produced arts and artists that are regional in their practice. The paper concludes that art schools have been the centre for manifestation of indigenous forms and artistic identity among Nigerian Painters.
\end{abstract}

KEYWORDS: Artistic Forms, Ethnicity, Nigeria, Painting

\section{INTRODUCTION}

Nigeria, like many countries in sub-Sahara Africa, is made up of a complex mix of ethnic, religious, and regional groups. This diversity creates a web of individual, intersecting and recursive identities, which are considered by many to be the main sources of the violent conflicts that frequently erupt there. Nigerians are known in terms of their ethnic affinities than any other identity and it's composed of various ethnic groups and cultures. Nigeria culture is informed by various forms of artistic and social endeavour such as the arts. In Nigeria, different art traditions have thrived and are still striving in various parts of the country. Adepegba identifies the sculpture traditions to include Nok, Igbo-Ukwu, Ife, Tsoede, and Benin as well as the stone carving traditions in the Yoruba and Ekoi areas of the country.

In the Northern Nigeria, specifically in Birnin kudu, and Geji near Bauchi, engravings depicting animals and human figures have been found. Art forms such as painting, drawing, printmaking, sculpture, photography, textile and others have reflected various cultural identities based on the regional groups. The art and culture of Nigeria embody the vivid image of the Nigerian way of life combined with the magnificent history of the past [1].
One of the major aspects of Nigerian art and culture lies in the fact that they draw their inspiration from the traditional folk heritage of the region. However, this study is limited to cultural identity of major ethnic groups in Nigeria. The largest, most populous and politically influenced ethnic groups in Nigeria: Hausa, Yoruba, Igbo, Ijaw, Kanuri and Ibibio. Within these groups, there are major groups with different languages, culture and lifestyle. Artists from each of these ethnic groups have reflected their identity through the use of forms in their painting. This invariably suggests what this paper described as regional Nigerian painting.

\section{METHODOLOGY}

Data for this study were obtained from field work and direct observations of paintings of different forms across ethnic divides in the various Nigerian Arts institutions of the various regions. It adopts qualitative approach to describe the nature of Arts among the regions of Nigeria.

\section{RESULTS AND DISCUSSION}

\section{Regional painting: historical overview}

The regional artist is anyone living and practising art in a regional location. This includes large regional centres, small towns, villages and the bush. Regionalism developed in America at a 
challenging time. The Great Depression was increasingly making life difficult for people across the country. Several artists working in the Midwest began painting the people, work atmosphere and life around them, predominantly rural and agricultural in nature. These artists were consciously pursuing a style different than the art then in fashion in urban art centers like New York City and Paris.

The work of the Regionalists was a search for distinctly American art. It was also a rejection of abstraction. Abstraction was art that didn't portray images or scenes found in the real world, and it was the major movement dominating European art at the time. Unlike abstraction, Regionalism was based on the real world of a specific place and time. In fact, some Regionalist artists described their work as having a goal of creating 'scenes of America.' While many artists working in the Midwest became known as Regionalists, three artists, in particular, became very associated with the style.

One of the most famous Regionalist artists was Grant Wood (1891 -1942), an Iowa-born artist who studied art abroad in Europe. Although he saw modern art as an abstraction, he rejected it, returning to Iowa where he was inspired by the farm life around him. Wood painted possibly the most well-known Regionalist painting, titled American Gothic, painted in 1930. Another Regionalist artist, Thomas Hart Benton (1889 - 1975), was born in Missouri and studied art in Chicago. Benton also spent time in Europe and painted in more modern styles before abandoning them in favor of his own style of realism. Benton portrayed farm life and working people as exaggerated curving figures. So his art was realistic in the sense of subject matter but not in rendering of form. He spent years painting and teaching in New York City before eventually returning to Missouri.

Nigeria is one nation whose culture is depicted through art forms such as dance, literature, music, arts and craft, fashion and more. Nigerian art takes to the world, where stone, wood and glass carving, pottery, wire works, and paintings are heavily explored. Each region in Nigeria reflects art that are related to their traditional culture. Nigeria draws its inspiration of their art from traditional folk heritage which are regional in nature.the Ibibio of SouthSouth of Nigeria there is also Insibidi codified message form; and Ulli, the Igbo symbolic form among the Igbo [2]. African art, mostly before Western influence recorded many of such coded message forms [3]. The ancient Egyptian tombs and vases; as well as the Nok, Benin and Ife sculptures of Nigeria are exemplary examples of this. For instance, the Nok pieces, which are the oldest sculptures produced in Sub-Sahara Africa [4] communicate cultural behaviours that are peculiar to the visual arts of the people. Similarly, the artists in Ile-Ife, the sacred city of the Yoruba of SouthWestern Nigeria, produced masterpieces of court art. The artworks were basically used for religious, sociopolitical purposes. Also, many were produced mostly in terracotta, wood, copper, bronze and stone [5]. They were of high technical and artistic quality. The realism and sophistication in material techniques tactically bring these works close to the classical Greek ideals of beauty. Attempts were made at producing life-size portrait of the Ooni (King of Ife) in full regalia, clad in woven textiles and wearing a lavish adornment of beads. Also, Benin art and other traditional Nigerian arts, as well as the arts of many other African groups, present the courtly splendor, magnificence and the power of kingship on one hand and religion, magic and the class distinction in the society on the other [6]. Each region uses indigenous forms to portray ethnic identity. This invariably produced arts or artists that are regional in their practices. However, due to diverse forms from geographical and educational background, there is needed to identify regional painting through regional art schools.

\section{Emergence of regional painting in Nigeria art schools}

The development of regional painting in Nigeria cannot be complete without the divergent view of Aina Onabolu and Kenneth Murray. Onabolu broke with the past by adopting new pictorial modes of representing the self as he imagined a future different from that of his ancestors. Murray resolutely resisted the new because it alienated the old and, more troubling, had the potential to level the imaginary boundaries between the irrevocably yet differentially modernizing Africa and Europe. Onabolu and Murray represented two oppositional visions of modern Nigeria art during Colonial period, while Onabolu pre-empted the postcolonial modernism of the mid-century. Murray's pedagogy is the belief that students should be encouraged to create art along purely African lines rather than be made to imitate European artistic styles and forms or be subjected to British examination standards. Artists such as Uche Okeke took to their regional forms to achieve distinctive identity. This study identified regional painting by the geographical locations of each art school.

During the period leading up to and following Nigerian independence in 1960, artists appropriated 
cultural and aesthetic traditions from around the country as a means of defining a new national identity. They drew upon narrates from Yoruba, Igbo, Hausa and other cultures and artistic traditions to inform the content and style of their works, manipulating tales from the past to produce a mythology for the present.This practice was defined as 'natural synthesis' by the Art Society at Zaria, an art group formed in the late 1950 s by Uche Okeke, Demas Nwoko, Simon Okeke, Bruce Onobrakpeya and other art students at Zaria in the northern region of Nigeria. Moving away from traditions steeped in colonialism, 'natural synthesis' merged the best of indigenous art traditions, forms and ideas with useful ones from Western cultures to create a uniquely Nigerian aesthetic perspective. The members of Art Society were later known as the Zaria Rebels, devised a program outside the University curriculum, where they thoroughly researched indigenous cultural and artistic traditions, produced works based on ethnic findings and met regularly to discuss the outcomes.

After the war, Okeke joined University of Nigeria, Nsukka, where he ran the Department of Fine and Applied Arts from 1971 to 1983 . Under his direction, Nsukka rose to prominence as a center of Nigeria's artistic creativity, drawing artists like the renowned El Anatsui to its ranks. At Nsukka, Okeke further developed his synthesis theory, encouraging students to research Nigerian art traditions to solve formal problems in their work. Under Okeke's supervision, Obiora Udechukwu manipulated Uli, and later nsibidi, another indigenous form of the region. Bruce Onobrakpeya in his case synthesized mythological, folkloric and popular themes from Urhobo as well as Yoruba cosmology. Some of his prints bear eclectic traits traceable to the adire motifs and ancient Benin plaques. However, Okeke's rigorous and intellectual inquiry into Uli influenced another generation of artists, including Tayo Adenaike, Olu Oguibe, Chika Okeke-Agulu and Marcia Kure, among others.The intensification of the search for Igbo-identity, using the Uli linear forms to depict radical socio-political and cultural subject matters is the hallmark of the art of this School of Art [7]. The contributions have been in the areas of propagation of visual arts as an instrument of development of society. Uli is known as an artistic cultural practice of the Igbo of Southeastern Nigeria [8]. This practice involves painting motif on the body and walls. Uli is disappearing in many Igbo villages.It should however be preserved as it communicates important cultural meaning (Plate 1).
Uli designs were painted by lgbo women on their bodies and as murals on clay walls [9].

The Ife School developed from the Ori-Olokun workshop, an informal workshop established to develop the artistic talents of Ife indigenes. The Ife School artists were trained to use materials from their immediate environment, which can be seen in their terracotta, granite and bronze works. This style flaunts patterns and designs peculiar to the rich artistic culture of Western Nigeria. The natural synthesis concept which gave rise to the other emergent art schools such as Ona School influenced the artistic production of this group.The School is noted for intellectualization of its works with vigorous emphasis on theoretical content in art form. Noted with cultural inspiration drawn from the Ife location, the School explores a rather diversity of creative exploration in the use of local materials, symbols and images which later developed into the exploration of Yoruba traditional symbols, motifs, structure and concept termed Ona by some of the 1980 s graduates.

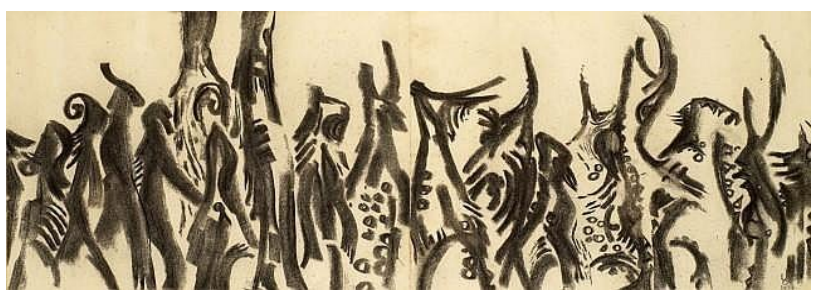

Plate 1. Uche okeke, March of the masquerade. Ink and brush on paper (Art Fact, 2010).

In Ona art, traditional art forms are transmitted into artistic production, by using them as a point of reference to create modern forms. With good draughstmanship and a mastery of aerial and linear perspective, windows were created in the works and more interesting solidity of forms was achieved without losing the presence of patterns all over the painting. The patterns are not after thought additions, but a systemic buildup of symbols, motifs and designs integrated within the structure of the composition [10].

Ona is the process of artistry and the word Ona is linked with others to capture the underlying meanings. Thus, the design work is called Ona while the designer is regarded as Oni-se-Ona (He who makes pattern) or Gbena-gbena (He who carves design) which could be seen in the area of sculpture. Ona is also relevant to aesthetic appreciation. The Yoruba word, Oju-Ona (eyes for design) describes the position of 'design consciousness' and critical appraisal. If Ona could be so dynamic in use, then it 
is supposed to enhance expression in painting. However, in most of the paintings of Ona exponents, there is a critical distortion in form and colour which actually negated the primary meaning of Ona concept. Ona concepts supposed to enhance the creativity input in contemporary Nigerian painting not only to serve as decorative object as seen in the work of Moyo Okediji, Kunle Filani (Plate 2).

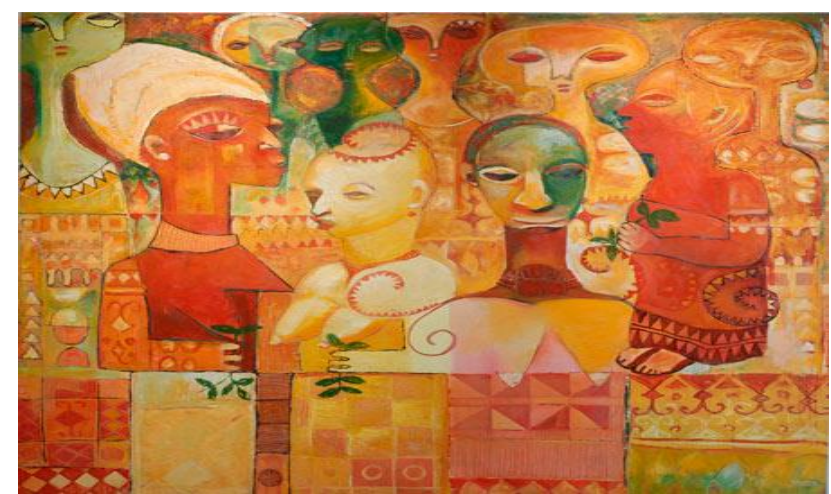

Plate 2. Tola Wewe, Race, Gender and sexuality in African art, Oil on board (Artist Archive, 2010).

The rejection of all forms of European artistic knowledge by some students of the Ahmadu Bello University, Zaria changed the course of our visual history. The Zaria School artists focused on Nigerian cultural themes and experiences of the North where the school is located. Zaria art School which has been noted with individualism in form depiction often time has been characterized by elongation of forms, abstraction and semi-realistic with northern architecture and human Figures. Their landscapes, most times reflect the grassland and Savannah vegetation of the north.

So long as an individual artist conforms to the general norms of artistic presentation, he will not think in a way that is out of the ordinary. When an artist has his own unique point of view and a keen perception that does not conform to the regular pattern, he will come up with a creative understanding. However, individuality in art practice encourages self-reliance, initiative, persistence and unique perceptions and new visionary ideas. All these are very useful to painters and therefore it is not surprising that many painters of Zaria art School are highly individualistic in the practice of painting. For example, Yusuf Grillo makes use of western art training in many of his paintings, combining western art techniques with Yoruba sculpture characteristic of angular representations. His form of paintings has always been the elongation of forms which are mostly women with little attention to details. Jimoh Akolo uses a limited colour palette which is rendered in cubistic manner that suggests a peculiar characteristic of the artist.

Also, Gani Odutokun engages in semiabstraction using aggressive brush strokes to suggest form in his painting. He also excludes detail representation in his painting but uses colour to dazzle the attention of the perceiving audience. Going by individuality perception of various graduates of the institution, therefore it is clear that there are diverse ethnic attributes in the works of different artists of the school (Plate 3).

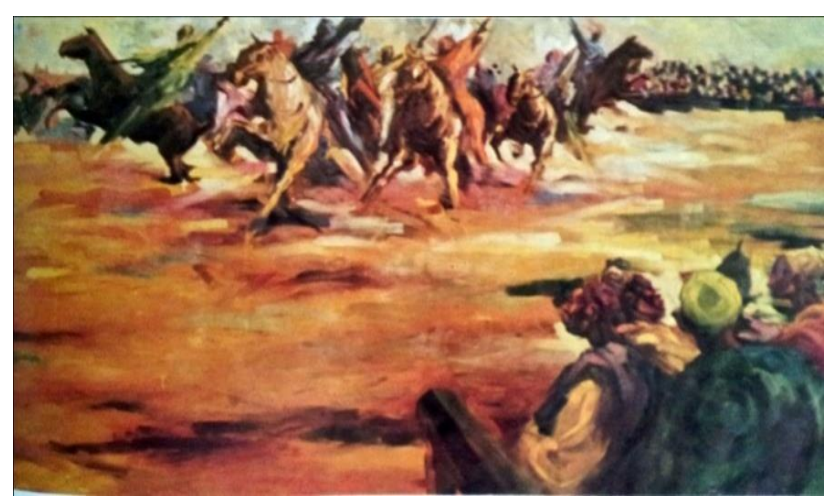

Plate 3. Gani Odutokun, Dubar. (Oil on board Greeting card Unicef, 1983).

Yaba school of thought in art practices has adopted the technique or style of naturalism and realism from inception through the efforts of the foremost teachers of the School. This school employs a realistic art form that is done in the narrative, and descriptive style is mostly done in accurate photographic realism. The School which is located in Lagos State, southwestern Nigeria, is based on an exceptional understanding of colour, and it is distinct for its almost accurate realistic representation of the activities of the area. Example of this can be found in the paintings of Kolade Oshinowo, Samuel Ajobiewe, Ebenezer Akinola, John Akintunde, Edosa Oguigo, Olumide Oresegun and others (Plate 4).

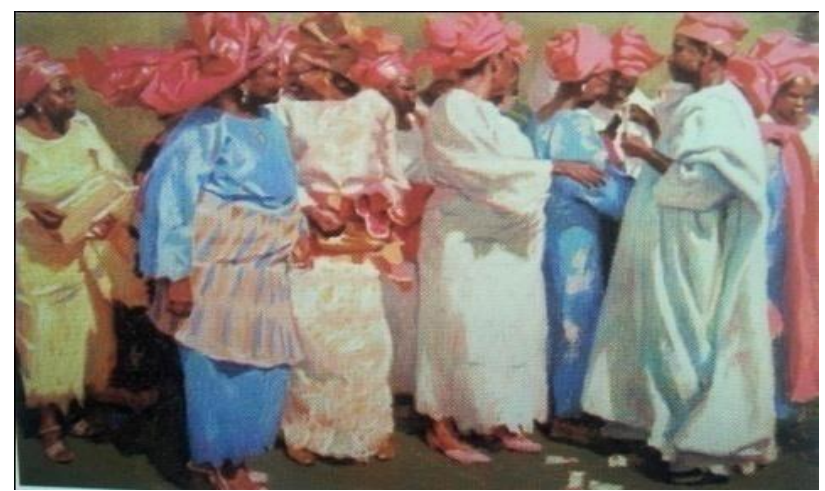

Plate 4. Samuel Ajobiewe, Baba Alaye. (Oil on Canvas) (Artist Archive, 2010). 
The ideologies of self-identity in contemporary Nigerian art is to be able to create an independent style that will be able to reflect true understanding of the process not to entirely abuse the process. For example, Onobrakpeya has discovered, innovated and perfected several techniques both in printmaking and relief sculpture that are uniquely Nigerian. Generally, printmaking is a fine art process of producing pictures from a plate which the artist has previously created. $\mathrm{He}$ has increased the techniques tremendously to reflect his unique selfidentity. So also in painting, artists have distinguished themselves in terms of styles in order to pick an identity that will uniquely be acceptable to the audience.

\section{CONCLUSION}

This paper established that each ethnic region in Nigeria has its own iconic identity that is manifested in various forms. The art schools of each region have been the centre for manifestation of forms of paintings in Nigeria. The Schools of art in Nigeria has distinctive style to depict elongation of forms, abstraction, semi-realistic with northern architecture that reflects grassland and savannah vegetation. Each region uses indigenous forms to portray ethnic identity and this invariably produced arts and artists that are regional in their practice. It concludes that ethnic identification was manifest in the use of forms in various regional art schools in Nigeria. Artists of different art schools reflect on various environmental issues which makes their painting distinctive.

\section{Competing interests}

The authors declare that they have no competing interests.

\section{REFERENCES}

[1]. Adepegba C (1992). Nigerian Art: Its Traditions and Modern Tendencies. Ibadan; Jodad Publishers. Google Scholar

[2]. Aniakor C (1988). The Contemporary Nigerian Artist and Tradition. USO: Nigerian Journal of Art, Vol. 2, No. 1 and 2 Lagos. pp 16-21. Google Scholar

[3]. Aniakor CC, Cole H. (1984). Igbo arts: Community and cosmos. Museum of Cultural History, University of California (Calif.). Google Scholar

[4]. Ekpo E (1977).Two thousand years of Nigerian Arts. Lagos. Federal Department of Antiquities. Google Scholar

[5]. Fagg.W (1973) In Search of Meaning in African Art, London. Primitive Art and Society. A forge (ed). Oxford University Press. Google Scholar

[6]. Frobenius L (1913). The Voice of Africa: being an account of the travels of the German Inner African Exploration Expedition in the years 1910-1912. Hutchinson \& Company. Google Scholar

[7]. Irivwieri G (2007) 'Nigerian Art. Evolution of Forms and Significance' Journal of Creative Arts, vol. 3, pp 24-37. Google Scholar

[8]. Ottenberg S. (2006) Igbo art and culture and other essay in Toyin Falola (ed), Eritrea; Africa World Press, Inc. Google Scholar 